\title{
The 13th European Colorectal Congress (\#ECCStGallen), 1-5 December 2019, St Gallen, Switzerland: Congress Report
}

\author{
M. Adamina ${ }^{1,2} \cdot$ J. Douissard ${ }^{3} \cdot$ J. Lange $^{4}$ on behalf of \#ECCStGallen Scientific Committee
}

Received: 26 March 2020 / Accepted: 6 April 2020 / Published online: 16 April 2020

(c) Springer Nature Switzerland AG 2020

\section{Congress report}

More than 1050 participants from 75 countries attended the 13th European Colorectal Congress, held from December 1st to 5th, 2019 in St. Gallen, Switzerland. The congress welcomed lectures discussing time-tested wisdom, updates in the management of complex situations, as well as innovative strategies and other contemporary topics. The dynamism of the field was underlined by over 100 posters submitted and presenting early stage research, clinical innovations, and reports of rare cases. The Congress and its Masterclass in Colorectal Surgery (\#ECCStGallen) were granted $26 \mathrm{CME} / \mathrm{CPD}$ credits by the Swiss Society of Surgery, the $\mathrm{nVnH} /$ Dutch Colorectal Society and by the Association of Surgeons of Great Britain and Ireland. Overall, 46 Expert lectures were given at another successful \#ColorectalSurgeryWeek. The \#ECCStGallen 2019 was further endorsed by the Swiss Association of Minimal Invasive Surgery (SwissMIS), the European Association of Endoscopic Surgery (EAES), and the European Crohn's and Colitis Organisation (ECCO). The full program of \#ECCStGallen 2019 can be found on the congress website www.colorectalsurgery.eu.

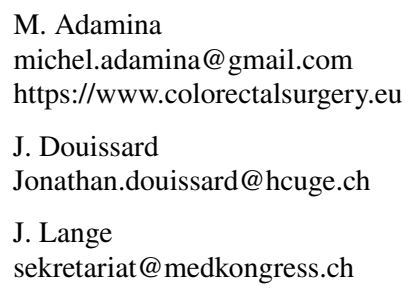

1 Department of Surgery, Colorectal Surgery, Kantonsspital Winterthur, 8401 Winterthur, Switzerland

2 Faculty of Medicine, University of Basel, Basel, Switzerland

3 Abdominal Surgery Department, University Hospital of Geneva and Medical School, Rue Gabrielle- Perret-Gentil 4, 1211 Geneve, Switzerland

4 Medkongress AG, Rorschacherstrasse 311, 9016 St.Gallen, Switzerland
The meeting started on Sunday with its Masterclass in Colorectal Surgery as part of the continuing education of colorectal surgeons in the broader spectrum of the European Board of Surgical Qualifications (EBSQ) in Coloproctology. The Masterclass is an intensive 1-day course intended to provide in-depth coverage of selected topics paramount to the safe practice of colorectal surgery. Didactic aspects were stressed and the interactive course can serve as a preparation to board certification, including the EBSQ Coloproctology, whose examination scheme was presented by Michel Adamina. Coffee, lunch, and pdf copies of the Masterclass presentations were offered to registered participants.

Highlights of the 2019 Masterclass included cutting edge updates on common pathologies, such as strategies regarding complex appendicitis presented by Justin Davies, decision-making around difficult stoma management addressed by Gabriela Möslein and Willem Bemelman (Fig. 1), and approaches to pelvic floor disorders discussed by Julie Cornish (Fig. 2). Technical points and controversies regarding transanal total mesorectal excision (taTME), complete mesocolic excision (CME), and lateral lymph node dissection were thoroughly addressed by leading experts Roel Hompes (Fig. 3), Paris Tekkis, and Peter Sagar, who shared their views and practice recommendations. André d'Hoore reported his experience in construction and salvage of colorectal anastomosis, including the most recent developments in anastomosis techniques in inflammatory bowel disease. Ronan O'Connell then discussed the timing of rectal cancer surgery following neoadjuvant radiochemotherapy in light of the growing literature. Last but not least, recent publications that have the potential to change and improve practice were discussed by Neil Mortensen, one of the giants of colorectal surgery.

The main congress opened on Monday 2.12.2019 with as session dedicated to diverticular diseases. We were fortunate to have Robin Spiller, an expert gastroenterologist with a focus on the pathophysiology of functional diseases and the role of infection and inflammation, to discuss etiology and 


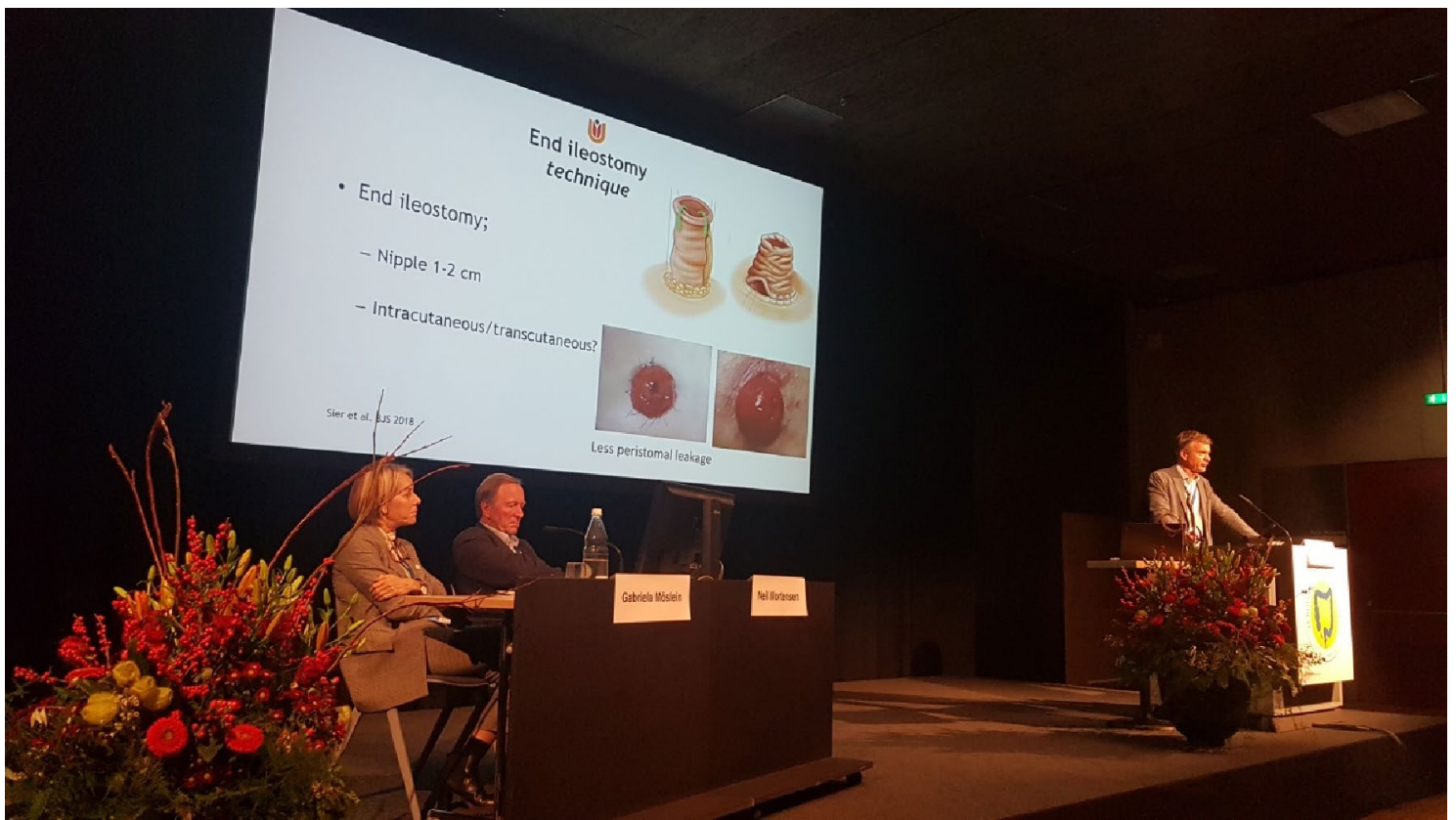

Fig. 1 Willem Bemelman reporting on all one needs to know about stomas but never dared to ask-many pearls from an expert shared with audience and chairs Gabriela Möslein and Neil Mortensen

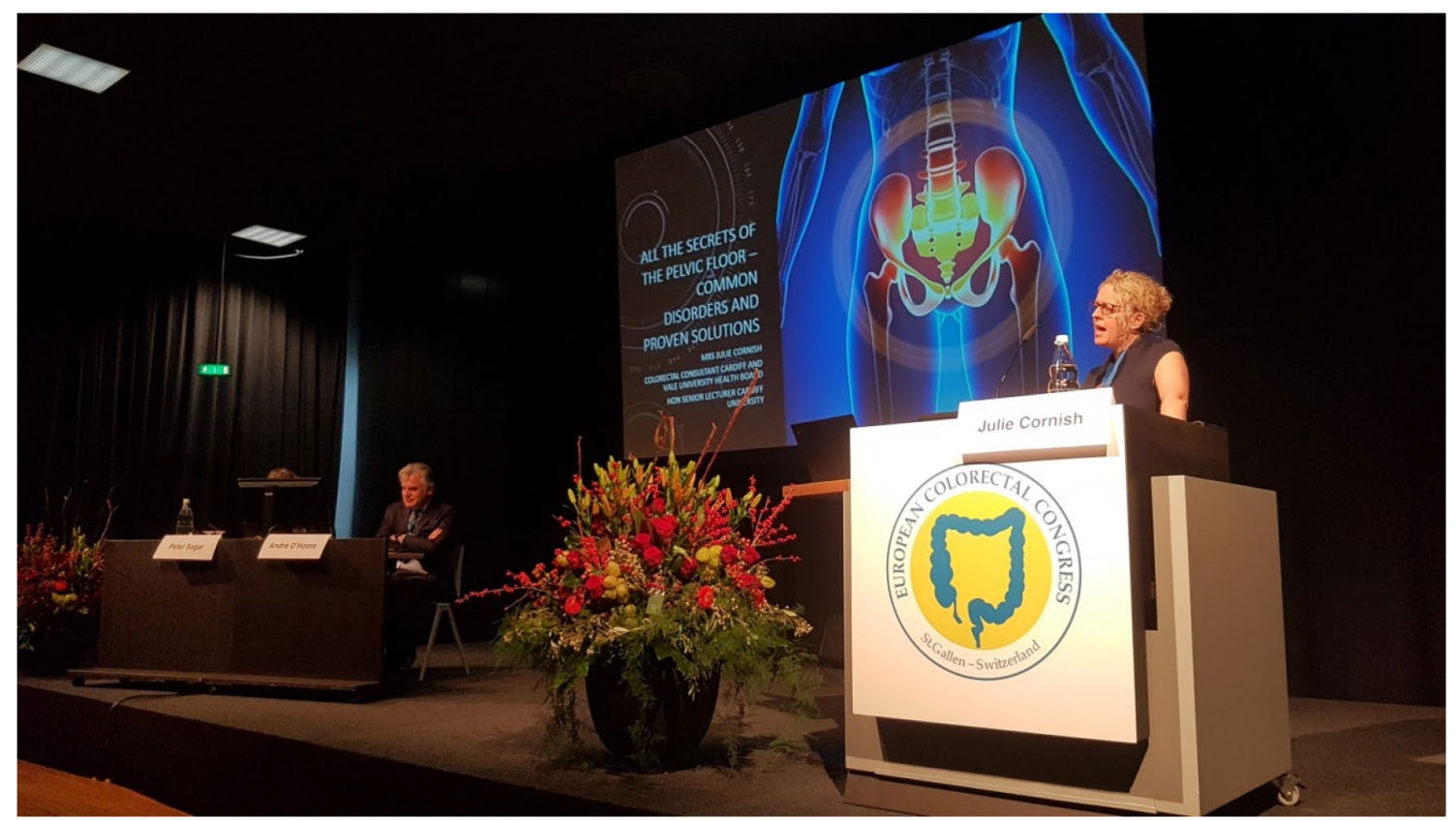

Fig. 2 Julie Cornish revealed all the secrets of the pelvic floor in the first session of the Masterclass chaired by André d'Hoore and Peter Sagar

non-operative management. Atypical diverticulitis was then addressed by Dieter Hahnloser, while Willem Bemelman emphasized the disruptive and progressive shift away from Hartmann's procedure in most emergency situations and the selective use of laparoscopic lavage, including purulent and fecal peritonitis. Broader adoption of primary resection and anastomosis, eventually associated with protective ileostomy, was thus supported in a talk thoroughly documented by an extensive literature review of the most recent trials [1]. Hartmann's procedure reversal can indeed lead to difficult operative situations and Roel Hompes detailed the technical options at hand. He underlined the improved outcomes of 


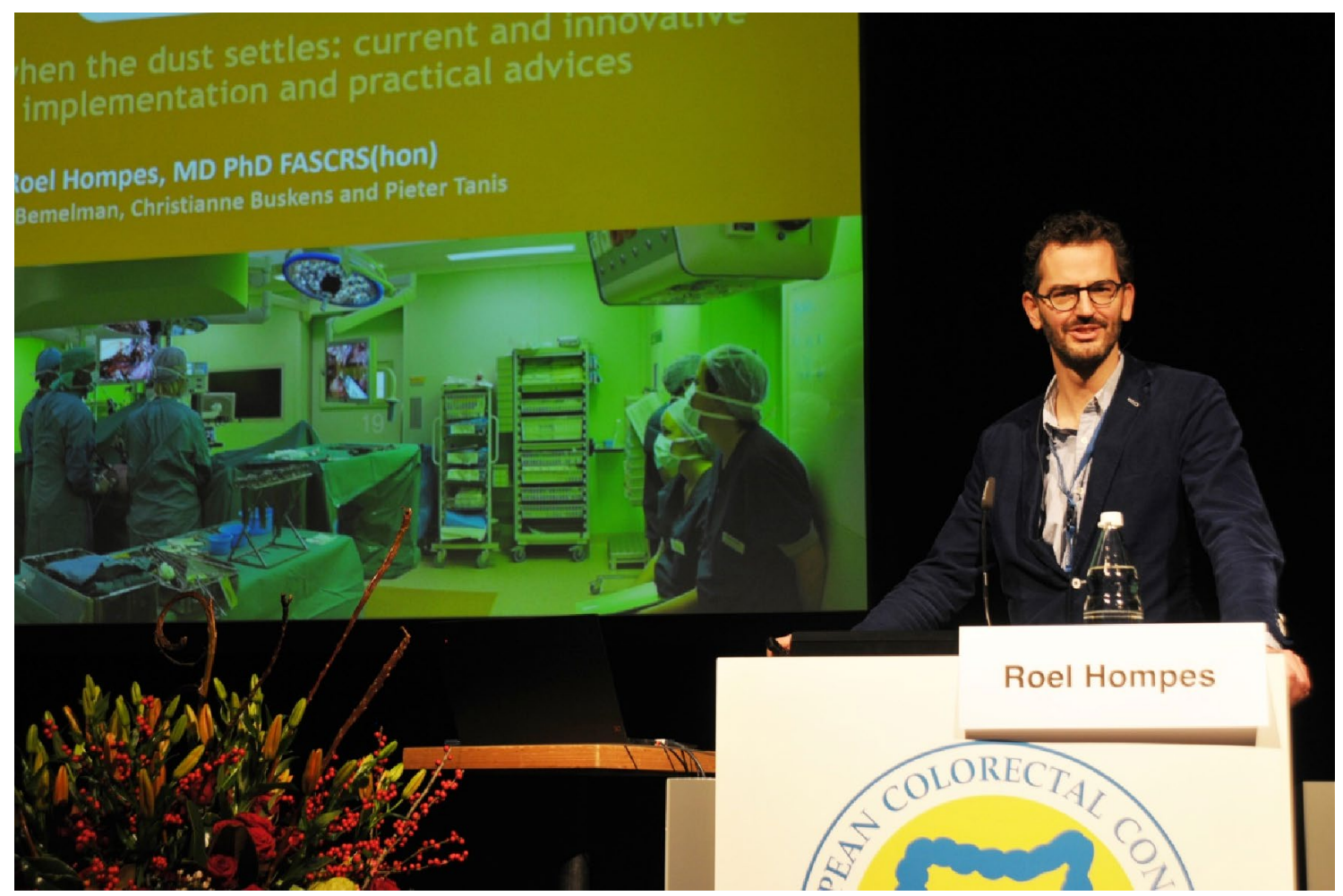

Fig. 3 Roel Hompes, who else, presents on taTME in 2020 — when the dust settles

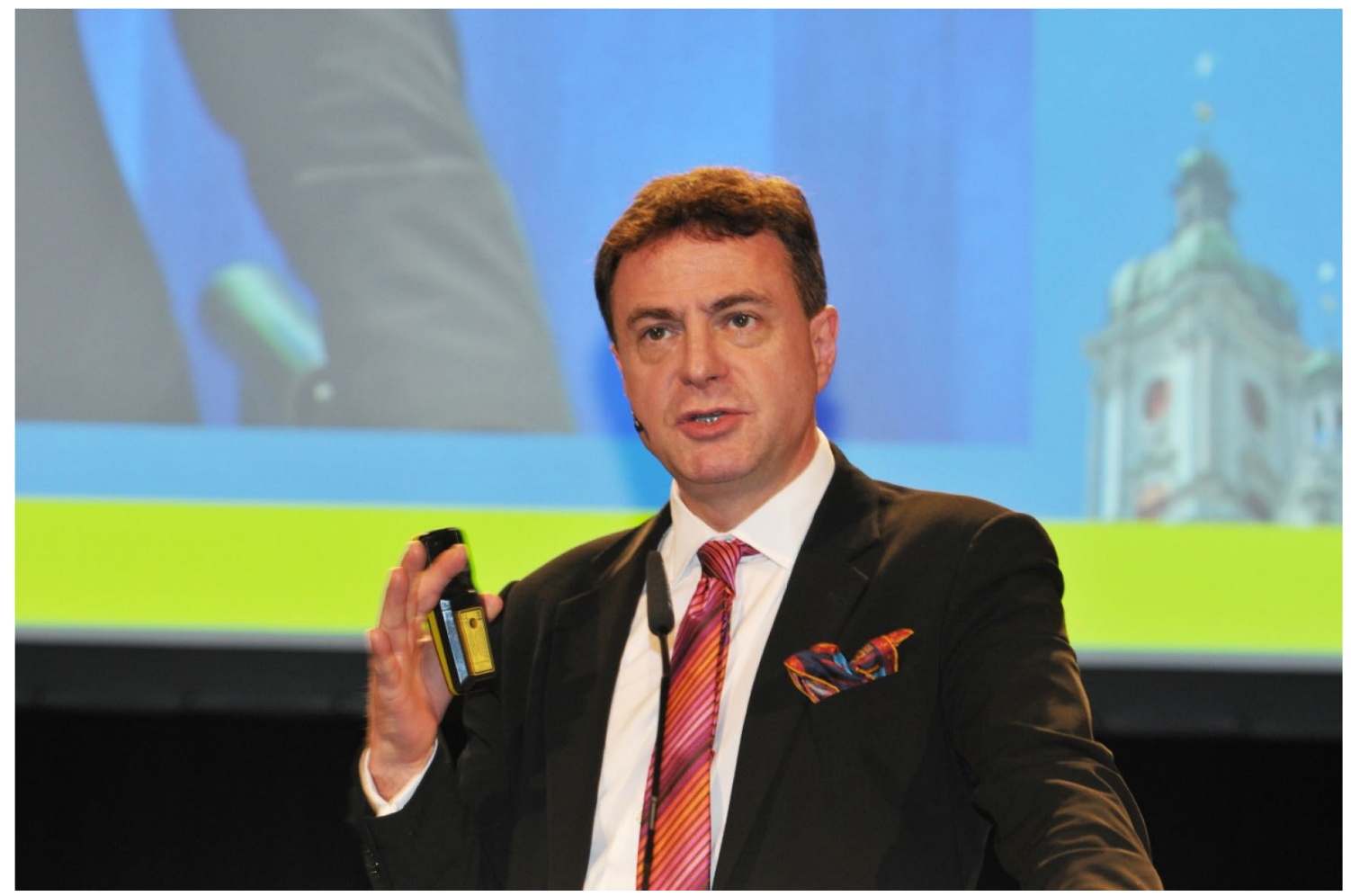

Fig. 4 Des Winter speaks about the surgeon's personality—influence on decision-making, risk-taking, and outcomes 


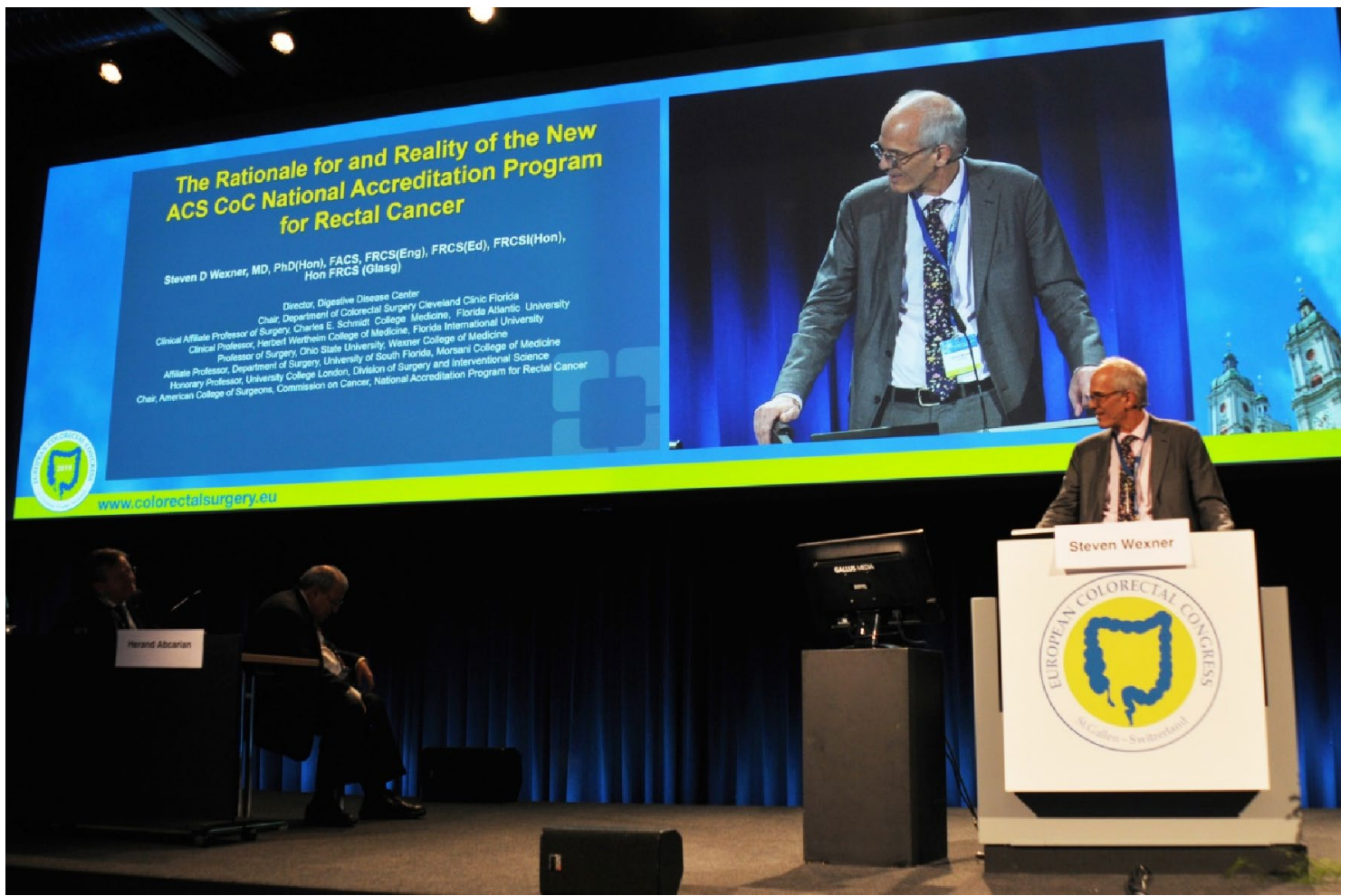

Fig. 5 Steven Wexner introduced by Herand Abcarian gave a superb Lars Påhlman Lecture
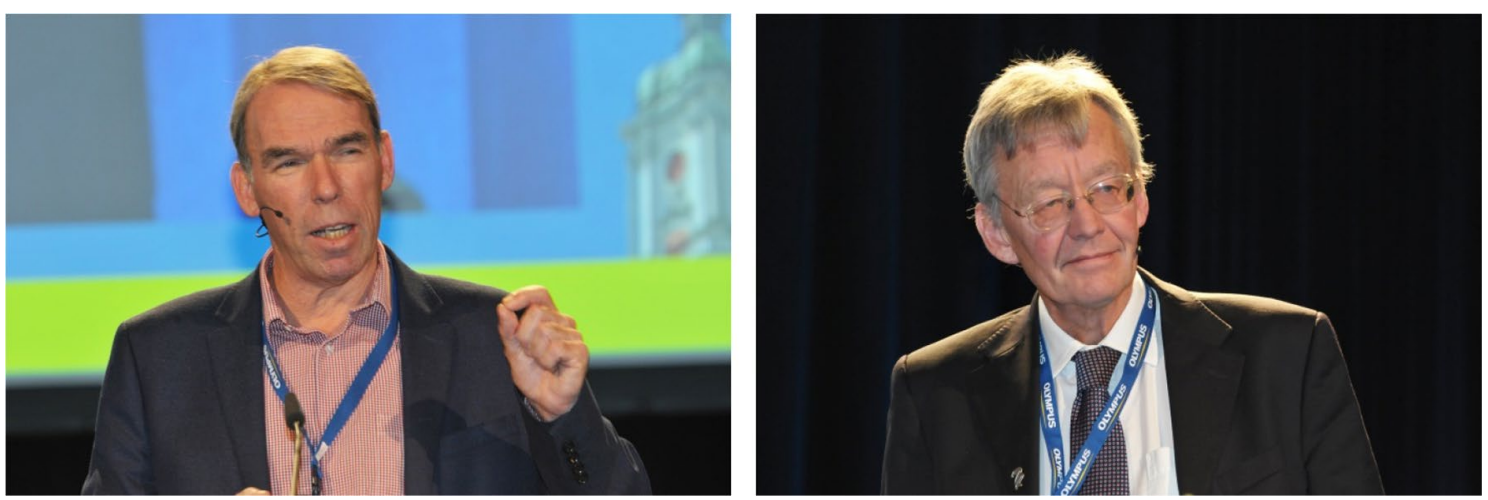

Fig. 6 First results of the FoxTrot randomized controlled trial on neoadjuvant chemotherapy for colon cancers reported by principal investigator Dion Morton and lead pathologist Philip Quirke

minimally invasive approaches, in particular the benefit of a transanal approach when facing a short rectal stump, while he underlined the meticulous preoperative planning required in considering these options.

The role of a surgeon's personality and emotional biases in the selection of surgical options was the subject of Des Winter's talk on Monday afternoon (Fig. 4). Age, experience, self-belief and emotional connection to the patient have particular roles in situations such as stoma formation or anastomotic leak management, although their impact can be variable and different depending on the observer's perspective. Conversely, objective arguments to help the decisionmaking process in colorectal surgery are more abundant than ever before. The presentation of a treatment algorithm for volvulus of the colon by Peter Sagar illustrated well the many options facing a clinician in everyday practice. $\mathrm{He}$ shared his experience and wisdom in dealing with this common emergency.

Later in the day, recent technologic outbreaks becoming available in the clinical setting such as advanced 


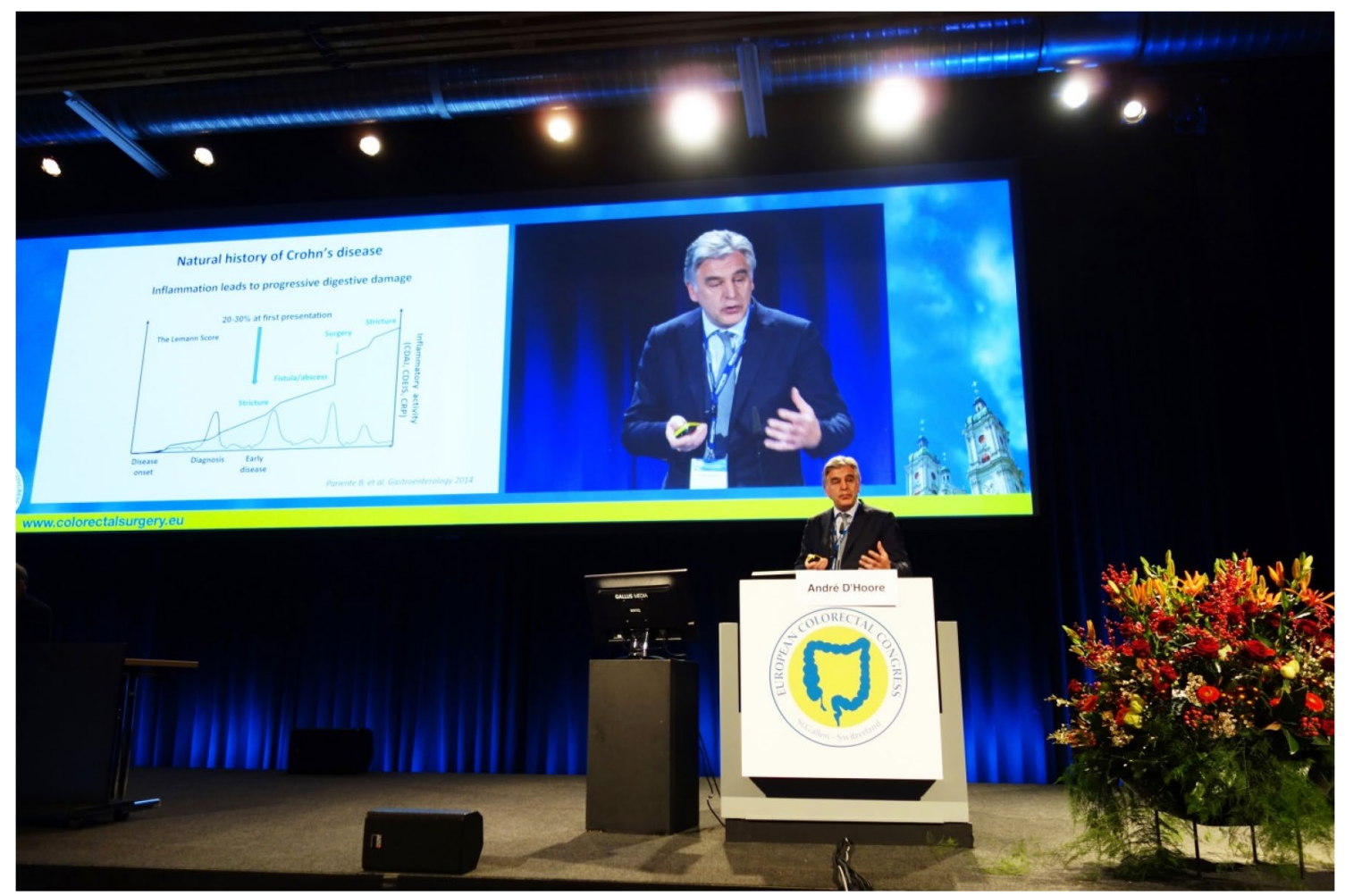

Fig. 7 André d'Hoore opens the session on inflammatory bowel diseases sponsored by ECCO with a presentation on Controversies in IBD

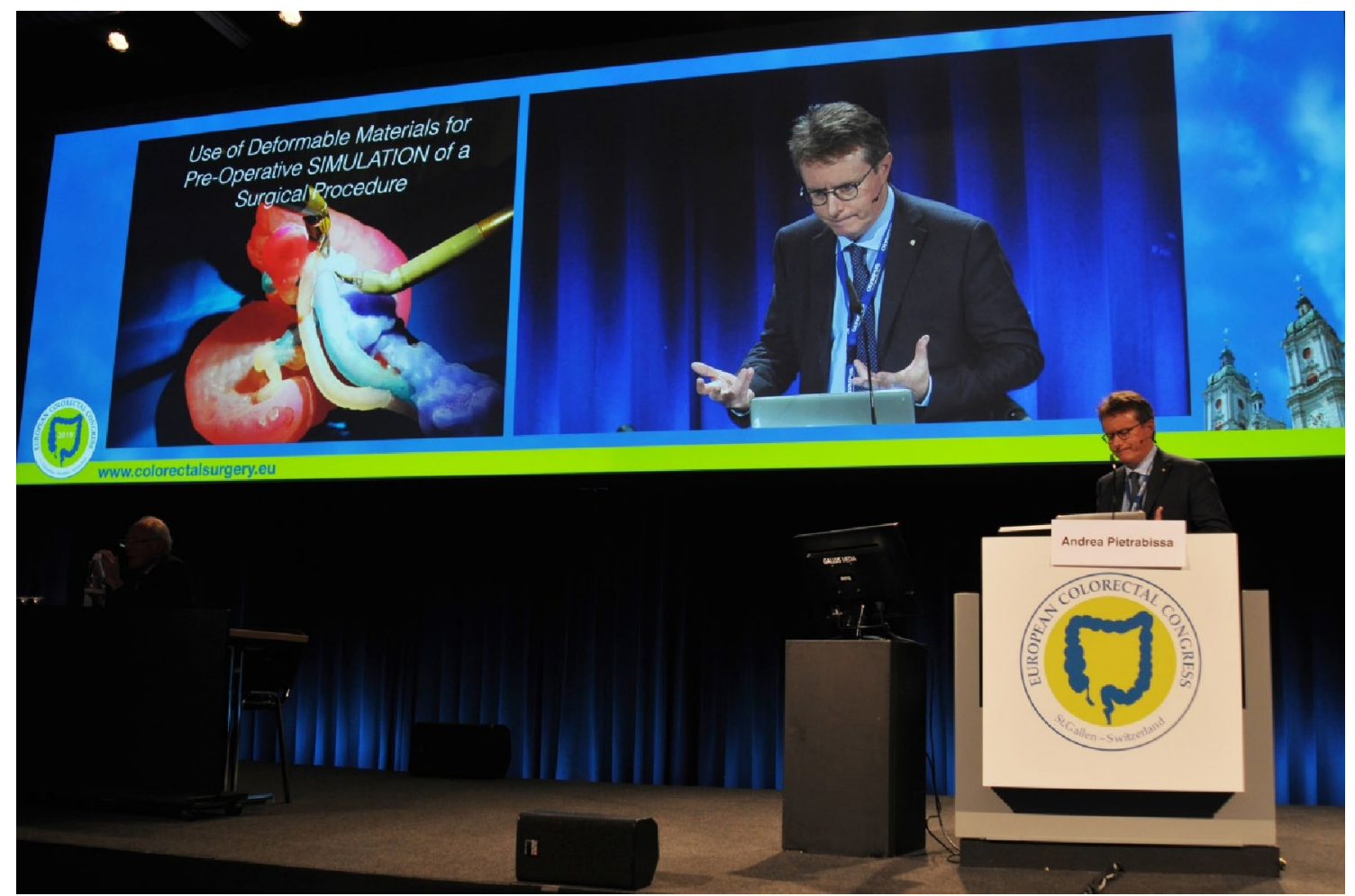

Fig. 8 Andrea Pietrabissa gives the EAES Presidential Lecture on clinical applications of 3D printing in surgery 


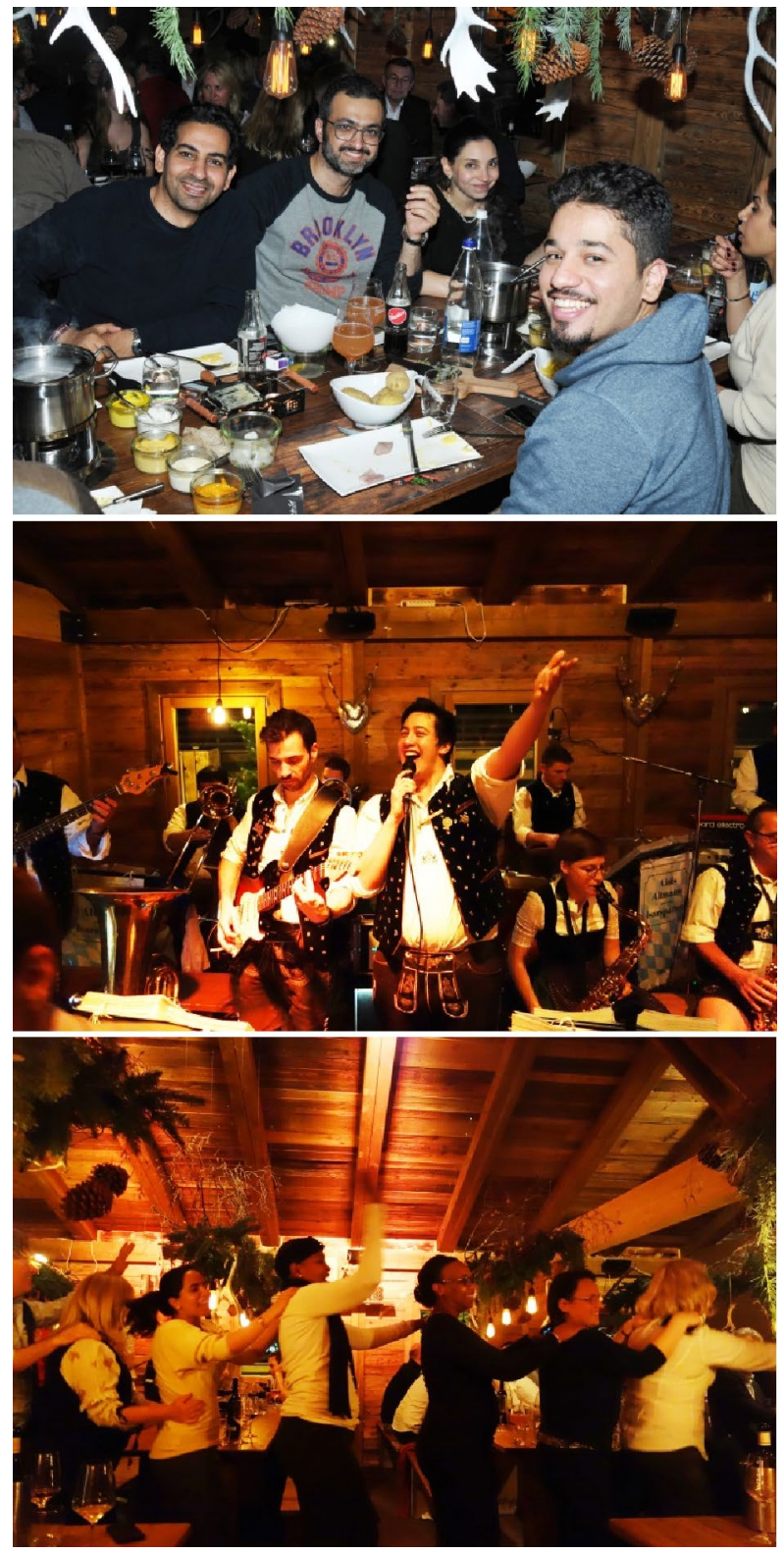

Fig. 9 Festive evening of the \#ECCStGalen 2019: there is more to remember - the chalet venue, live music, and a great ambiance made for a cheerful evening

perioperative and intraoperative imaging to guide oncologic resections were reported by Cornelis van de Velde, whereas gene-guided tailored therapy for hereditary colorectal cancer entering clinical practice was presented by Gabriela Möslein. These presentations echoed with this year's Lars Påhlman lecture concluding the second day of the congress. Herand Abcarian first broadcasted an interview with the late Lars Påhlman who discussed his genuine curiosity and passion for improving patients' lives and for rectal cancer surgery. Steve Wexner then gave an outstanding Lars Påhlman lecture (Fig. 5) and described the benefits and setting up of standardization and centralized accreditation of rectal cancer programs, along with the superior outcomes observed when using this approach in the United States [2].

Tuesday morning 3.12.2019 was dedicated to innovative approaches to complex oncologic situations. Amjad Parvaiz started off and compared the pros and cons of robotic rectal cancer surgery vs conventional laparoscopic surgery with unabated enthusiasm. Yet, the data available did not allow a firm conclusion, although ergonomic benefits for the surgeon were evident. Paris Tekkis then spoke about robotic multivisceral resections in locally advanced rectal cancer, which could expand the possibilities of minimally invasive resections in patients historically considered only for an open approach. Finally, Vic Verwaal, who has published randomized trials on cytoreductive surgery both in colorectal and ovarian cancers, summarized the lessons learned in two decades of practicing hyperthermic intraperitoneal chemotherapy.

Dion Morton and Philip Quirke then introduced another disruptive concept showing promising results: neoadjuvant chemotherapy for advanced colon cancer (Fig. 6). They revealed the early results of the FOxTROT randomized controlled trial, comparing neoadjuvant chemotherapy (6 weeks FOLFOX, surgery, then 18 weeks FOLFOX) to a standard approach (surgery followed by a 24 weeks FOLFOX protocol) for stages II-III colon cancer [3]. In 1'052 patients, it resulted in histological downstaging and 50\% reduction of incomplete resections, thus opening the way to a new approach in the armamentarium against advanced colon cancer. Of course, one of the main limitations of this approach is its non-applicability to obstructive colon cancer, which still accounts for a significant proportion of colon cancers. Discussing this clinical situation, Neil Mortensen's after lunch lecture- "Rush to the OR or stent and dine?"- -showed that stents in obstructive colon cancer should be broadly considered, both as a bridge to curative surgery or as a palliative option with minimal impact on quality of life. With an obstruction relief rate of $82 \%$, low complication and low stoma rates, and no oncological downsides, his thorough review advocates that surgeons to skip dinner less often.

Tuesday afternoon was then dedicated to controversies and current developments in inflammatory bowel disease (IBD). André d'Hoore debated on the surgical treatment of Crohn's disease, including timing and place of surgery in stricturing and non-stricturing ileocaecal diseases, one of the hot topics of the moment (Fig. 7). Innovative predictors of good surgical response were identified, such as microbiome modifications and response to the newest medical treatment. These variables impact the course of the disease and may be combined with established predictors into a decisional algorithm to individualize surgical approaches to Crohn's disease. Tailored care was also at the heart of the discussion on how to handle dysplasia in IBD, presented by Janindra 


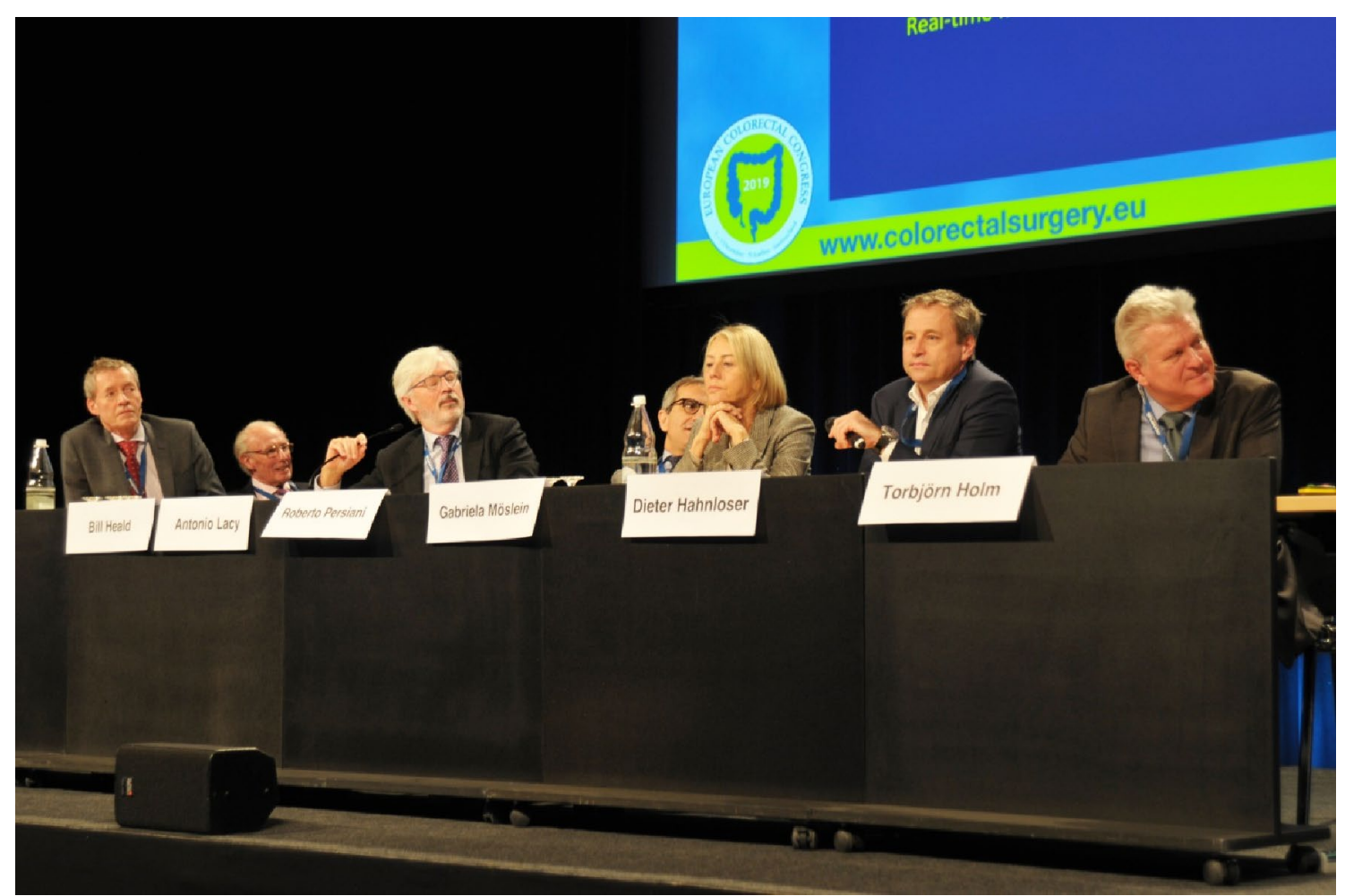

Fig. 10 Challenging cases brought by Herand Abcarian tested a panel of international experts made up of Gabriela Möslein, Bill Heald, Antonio Lacy, Roberto Persiani, Dieter Hahnloser, Torbjörn Holm, and Brendan Moran

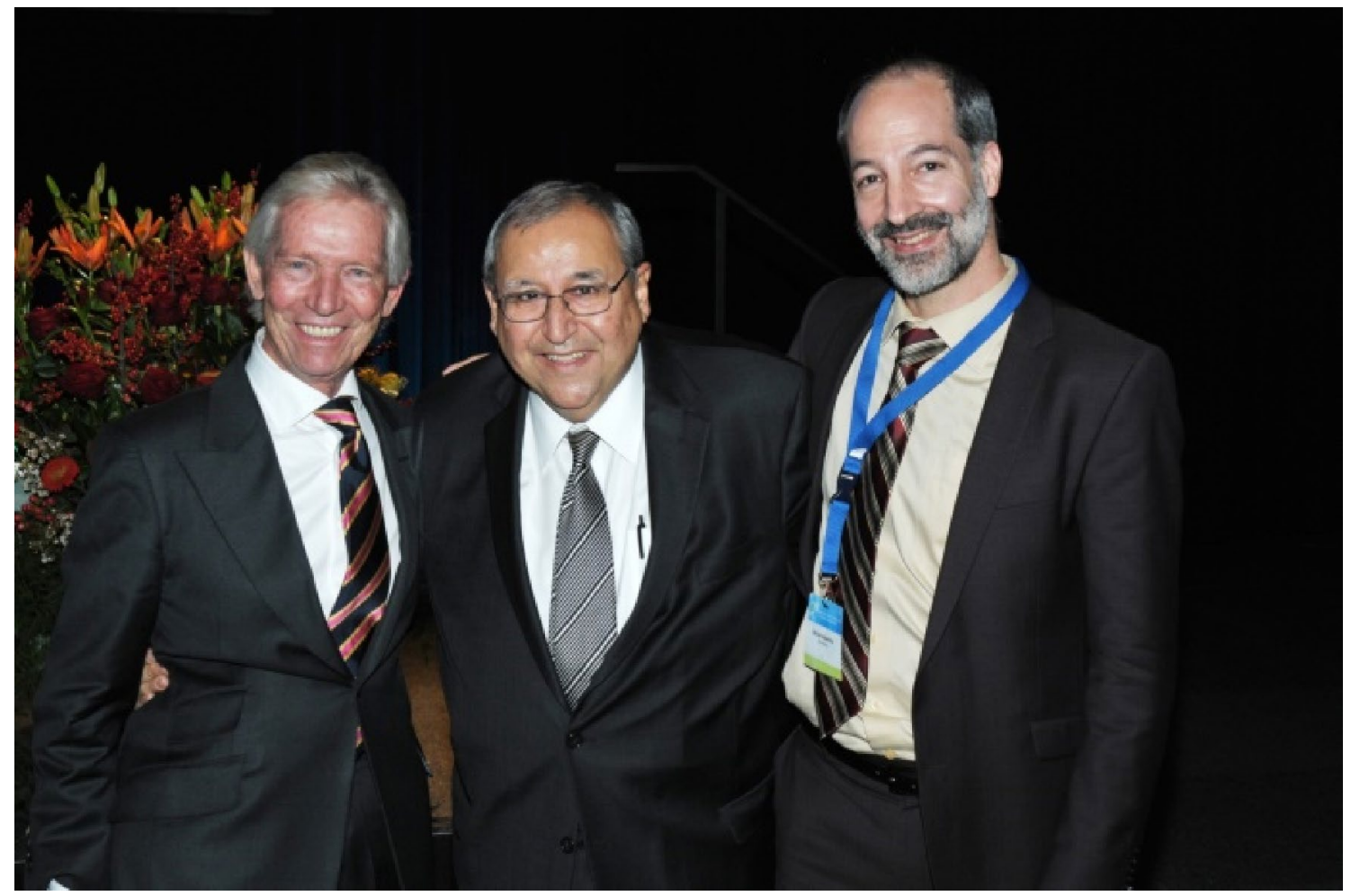

Fig. 11 Jochen Lange, Herand Abcarian, and Michel Adamina—Scientific and Organisation Committee—the \#ECCStGallen is starting! 
Warusavitarne, who devotes his practice exclusively to IBD patients. Justin Davies then gave a broad review of stateof-the-art practice in perianal Crohn's disease, emphasizing the importance of appropriate and immediate surgical care, including when necessary, a defunctionalizing stoma. Finally, Gerhard Rogler demonstrated the high potential of mesenchymal stem cell therapy which can achieve a 50\% remission rate, that can rise to $67 \%$ when associated with anti-TNF treatment [4].

Wednesday morning 4.12.2019 started off with a fascinating lecture from Ronan O'Connell. Taking us step by step through the basic principles of anastomotic healing, then discussing potential interactions of gut bacteria with these mechanisms, he presented anastomotic leakage as an infectious disease mediated by an imbalance in gut microbiota. Taking into account the importance of gut microbiota equilibrium in the anastomotic healing process, he proposed an explanation of the absence of benefits obtained until now with non-discriminant strategies of broad-spectrum oral antibiotics and bowel preparation [5]. This was another eyeopening presentation with high potential in clinical practice.

Another role of gut microbiota, its impact in colorectal cancer pathogenesis, was presented by Philip Quirke. He covered the latest findings from causality relationship to prevention, screening and treatment opportunities. Here again, a rapid increase in knowledge was witnessed and complex interactions were discovered with clinical implications in sight.

The morning then turned robotic again, with Antonino Spinelli discussing the cost-effectiveness of the surgical robots currently available and Alberto Arezzo reporting the latest developments of an innovative, proprietary robotic system. Last, Filip Muysoms, very well known for his expertise in hernia surgery, presented further applications of surgical robots to address complex abdominal wall reconstruction.

In the afternoon, Richard Brady explained the use, potential abuse, and above all the tremendous value of social networks in clinical and scientific surgery-his lecture on coloproctology 4.0 - the networked surgeon was followed with great attention.

Patient reported outcomes and values were at the heart of Isacco Montroni's lecture on Wednesday afternoon. Considering the high frequency of frailty in the ever-growing population of elderly patients undergoing oncologic surgery, he proposed to focus on what matters most for these patients: quality of life improvement and functional recovery. Through the prospective GOSAFE study [6] reporting 504 unselected elderly patients undergoing major oncologic surgery, he showed that one-third of these patients suffered functional decline 90 days after successful surgery. Functional decline correlated strongly with preoperative frailty evaluation, so that he advocated for a change in clinical practice, namely a systematic evaluation of frailty and a focus in the frail on quality of life improvement and functional recovery over classical oncologic outcomes.

The mystery of pelvic endometriosis was then addressed by Eric Rullier, the colorectal surgeon being a frequent partner of the gynecologist who at times may require our skills and understanding of bowel surgery principles. Yet, as for any cooperative work, it is important for the surgeon to understand the peculiarity of endometriosis and the needs of both patient and gynecologist to reach the best possible outcomes.

The fourth day of \#ECCStGallen came to its close with the EAES presidential lecture given by Andrea Pietrabissa. He showed amazing applications of 3D printing using soft deformable materials that allow highly realistic preoperative planning and training for complex procedures, such as complete mesocolic excision or solid organ transplantation (Fig. 8). But he also reminded us that despite the profusion of technologies available in developed countries and the benefits they procure to our patients, nearly 17 million patients die every year worldwide because of the inability to get surgical care. The \#ECCStGallen acknowledges this tragic situation and partners since many years with Médecins Sans Frontières (MSF, https://www.msf.org/) to promote global surgery and access to surgical care wherever and whenever needed.

Wednesday was also the day of the festive evening of the \#ECCStGallen, a very enjoyable moment spent together in a chalet-style venue with traditional Swiss food, ice skating, and a great party to warm up the night and hearts after having spent 4 days together sharing knowledge and clinical experience (Fig. 9).

The fifth and last day of the congress saw a firework of important lectures, starting on Thursday morning 5.12.2019 with Torbjörn Holm, who discussed management of locoregionally advanced colorectal cancer, capitalizing on his huge experience in dealing with these exigent situations. Clinical challenges were kept on the agenda as a round table chaired by Herand Abcarian tested the wisdom of a high-profile expert panel made up of Gabriela Möslein, Bill Heald, Antonio Lacy, Roberto Persiani, Dieter Hahnloser, Torbjörn Holm, and Brendan Moran (Fig. 10).

Back in St.Gallen for his knowledge of cutting edge technologies, Michele Diana detailed the current concepts in machine learning and use of artificial intelligence in healthcare. Picturing the great successes of this technology in medical diagnosis, he also underlined the challenges that artificial intelligence has to overcome in the specific field of surgery. The central limiting factor to date remains the difficulty gathering sufficient amount of high quality data in a field where every detail might count and have an impact on outcomes. Automated intraoperative data collection systems were presented that might solve this issue. 
The very last session of \#ECCStGallen alternated again innovative thinking and time-tested wisdom. Antonio Lacy gave his views on technical pearls and typical mistakes in minimally invasive colectomy, showing patterns of errors and better approaches, while Roberto Persiani talked about the right anastomotic technique in colon surgery, settling for intracorporeal side-to-side stapled anastomosis whenever possible.

Understanding anatomy is the key to safe and efficient surgery, a truism known by most surgeons. Calvin Coffey's lecture described the mesentery as a continuum uniting all digestive organs through anatomical dissections and 3D computerized reconstructions. He introduced the role of this least-understood, yet central organ in the pathogenesis and spreading of diseases such as Crohn's disease and colorectal cancer, as well as implications for endoscopic, radiologic, and surgical practice.

The last lecture was given by Brendan Moran, who talked about precision surgery: past, present, and future, reviewing achievements and developments as we enter into a new surgical era. Going as far as science and technology allow us to better serve our patients continues to provide a strong impetus in the rapidly evolving field of colorectal surgery, along with the overriding principle of patient' safety and an increased perception of the importance of patients reported outcomes, which were reflected in all the presenters' lectures.

The \#ECCStGallen 2019 closed with the presentation of the Poster Award of EUR 2000 by Michel Adamina to Dr. Min Jung Kim from Seoul, Republic of Korea, for her work on "Oncological Impact of Lateral Lymph Node Dissection After Preoperative Chemoradiotherapy in Patients with Rectal Cancer'. All accepted abstracts were published in a separate issue of Techniques in Coloproctology [7]. The Scientific and Organisation Committee thanks wholeheartedly Faculty and Participants for travelling to St.Gallen and interacting for another successful \#ColorectalSurgeryWeek (Fig. 11). Also, we thank Evelyne Thür and Claudia Franco from the Congress management for their appreciated support and commitment to the success of \#ECCStGallen 2019.

\section{Outline-14th European Colorectal Congress of St. Gallen, 29.11.2020- 2.12.2020}

In spite of the current Covid-19 pandemic, we are working to make of \#ECCStGallen 2020 another successful \#ColorectalSurgeryWeek - the $14^{\text {th }}$ European Colorectal Congress of St. Gallen. In a concentrated program over 4 days, we will start on Sunday 29.11.2020 with our traditional Masterclass in Colorectal Surgery and introduce a separate full-day Masterclass in Proctology held on Sunday, too. The main congress will take place from Monday 30.11.2020 to Wednesday 2.12.2020. The congress program and information can be found on the \#ECCStGallen website www.color ectalsurgery.eu, together with free access video lectures and the St.Gallen Consensus on Safe Implementation of transanal total mesorectal excision [8]. Overall, about 50 state-ofthe-art lectures by leading international experts will be given during the St.Gallen \#ColorectalSurgeryWeek.

We are looking forward to welcoming you in St.Gallen in December 2020!

\section{Compliance with ethical standards}

Conflicts of interest Michel Adamina and Jochen Lange declare that they have no conflict of interest or financial ties to disclose. Jonathan Douissard has no conflict of interest or financial ties to disclose pertinent to this work. Outside the scope of this work Dr. Douissard reports non-financial support from Intuitive Surgical Inc., a research grant from Intuitive Surgical Inc., and personal fees from Verb Surgical Inc.

Ethical approval This article does not contain any studies with human participants performed by the authors.

Informed consent Informed consent is not applicable for this Congress Report.

\section{References}

1. Lambrichts DPV, Vennix S, Musters GD et al (2019) Hartmann's procedure versus sigmoidectomy with primary anastomosis for perforated diverticulitis with purulent or faecal peritonitis (LADIES): a multicentre, parallel-group, randomised, open-label, superiority trial. Lancet Gastroenterol Hepatol 4:599-610

2. Antunez AG, Kanters AE, Regenbogen SE (2019) Evaluation of access to hospitals most ready to achieve national accreditation for rectal cancer treatment. JAMA Surg 154:516-523

3. Seymour MT, Morton D, on behalf of the International FOxTROT Trial Investigators (2019) FOxTROT: an international randomised controlled trial in 1052 patients (pts) evaluating neoadjuvant chemotherapy (NAC) for colon cancer. J Clin Oncol 37:3504-3504

4. Panés J, García-Olmo D, Van Assche G et al (2018) Long-term efficacy And safety of stem cell therapy (Cx601) for complex perianal fistulas in patients with Crohn's disease. Gastroenterology 154:1334-1342.e4

5. Koskenvuo L, Lehtonen T, Koskensalo S, Rasilainen S, Klintrup K, Ehrlich A, Pinta T, Scheinin T, Sallinen V (2019) Mechanical and oral antibiotic bowel preparation versus no bowel preparation for elective colectomy (MOBILE): a multicentre, randomised, parallel, single-blinded trial. Lancet 394:840-848

6. Montroni I, Rostoft S, Spinelli A et al (2020) GOSAFE—geriatric oncology surgical assessment and functional rEcovery after surgery: early analysis on 977 patients. J Geriatr Oncol 11:244-255

7. Adamina M, \#ECCStGallen Scientific Committee (2020) Abstracts presented at the 13th European Colorectal Congress 
(\#ECCStGallen), 1-5.12.2019, St.Gallen, Switzerland. Tech Coloproctol. https://doi.org/10.1007/s10151-020-02193-x

8. Adamina M, Buchs NC, Penna M, Hompes R, St. Gallen Colorectal Consensus Expert Group (2018) St. Gallen consensus on safe implementation of transanal total mesorectal excision. Surg Endosc. 32(3):1091-1103
Publisher's Note Springer Nature remains neutral with regard to jurisdictional claims in published maps and institutional affiliations. 